with the palms facing outwards. Begin again and repeat half to dozen times.

4. Keep the arms down, the palms touching the sides, slowly turn the psims outwards as far as they will go, and -slowly bring them back to the sides. This may be done six or eight times. This exercise, apparently so simple, expands the chest and presses together the shoulder blades.

The report ${ }^{2}$ of the Interdepartmental Committee on the model course of physical exercises presented to Parliament last year fully recognized the importance of breathing exercises, and the following passages from the syallabus drawn up by the Committee may be quoted :

The object of such exercises is the healthy functioning of the lungs, not merely increase of chest capacity. The vital measurement is not that of chest capacity simply, but of the difference between the full and the empty chest. Hence breathing exercises - which may, however, be conjoined with the exercises of the upper limbs already referred toare the more important, and the power of emptying the chest should be cultivated.

The breathing exercises as mere imitative movements may be begun on the child's first admission to school, the formation of habits of -correct nasal breathing being a matter of as great importance as any other department of infant school work.

It may be useful to reproduce here the syllabus of breathing exercises recommended by the Committee.

DeEp Breathing Exhrises.

These exercises are of great value, and should form part of the daijy training of every scholar. It is of great importance that the correct method of nasal breathing should be taught from the beginning of eachool life.

x. For Infants, a simple imitative exercise is the most easily acquired.

The infants, standing or sitting, and watching the teacher, place the left hand over the pit of the stomach and breathe in as she does, noticing the hand rise during inhalation. The child then breathes out slowly, the hand at the same time sinking. On each occasion the teacher must watch the class carefully, and note that all the mouths are firmly closed, and that all breathing is through the nostrils only.

This exercise should be repeated about six times at least twice daily.

v. For Older Pupils.

The teacher, starting from the position of attention, should see that all the mouths are firmly shut; then on the command Breathe-In (slowly given) instruct the pupils to breathe in slowly and dceply through the nostrils only, until the chest is fully expanded ; then on the command Breathe-Out (slowly given) to breathe nut quietly and steadily; this exercise should be repeated about ten times at least twice daily. When the exereise is repeated the commands In, Out only should be used.

Note - Care must be taken that during inhalation the head and chest Do not thrown too far back, nor the abdomen thrust forward.

When the exercise has been thoroughly acquired, it can be gradually combined with the slow arm movements, which bring into play the muxiliary muscles of respiration.

3. Combined Breathing and Slow Arm Exercises.

When a combined movement is used, the caution, With Deep Breatking, should always precede the command for the arm movements - for example, With Deep Breathing, Arms Sideways Raise. The arm movements employed should follow the rhythm of normal respiration (inhalation, exhalation-pause ; inhalation, exhalation-pause), etc, and the breathing act must not ba made to follow any artificial or arbil rary rhythm like that of music. It is also impossible that all members of a class should do the movements in absolute unison, for no two persons breathe naturally exactly alike.

The most suitable arm movements to combine with the deep breathing exercises are:

With Deep Breathing-Arms Side:nays Raising.

With Deep Breathing, Arms Sideuays-Raise (One).-Raise the arms as rin 50 , and at the same time breathe in slowly through the nostrils until the chest is fully expanded.

Lower (Two).-Breathe out naturally, and at the same time lower the anms to the sides.

(a) This exercise may also be combined with Ifeels Raising, the commands being With Deep Breathing, Arms Sideways Raising, Heels and Arms -Raize (One) ; Lower (Two).

With Deep Breathing-Arms Silleways and Lpward Raising. (To be done as a continuous movement.)

With Deep Breathing, Arms Sideways and Upward-Raise (One).-Raise the urms as in 53 , and at the same time breathe in slowly through the nostrils until the chest is fully expanded.

Lower (Two) - Breathe out naturally, and at the same time lower the arms sideways and downward.

(a) This exercise may aleo be combined with Heels Raising, the commands being With Deep Breathing, Arms Siderays and Upward, Heels and Arms-Raise (One); Lower (Two).

2 London: Wyman and Sons; Kdinburgh: Oliver and Bogd; and Dublia: E. Ponsonb5, roc4. [Bd. 2032j. 6d. The report was noticed in the BRITISH MEDICAL JoURAal, April 30 oth, rgc4, p. Ic26.
With Deep Breathing-Arms Circling.

With Deep Breathing, Arms Circling-Raise (One)-Kaise the arms as in $5_{2}$ and, at the same time, breathe in slowly through the nosirils until the chest is fully expanded.

Lower (Two).-Breathe out naturally, and at the same time lower the arms to the sides as in 54 .

(a) This exercise may also be combined with Heels Raising, the commands being With Decp Breathing, Arms Circiing, Hee's and ArmsRaise (One); Lower (Two).

N.B. Breathing Excrcises should always be taken at the end of a physical training lesson, in order to prepare for rest, and also to aid in the elimination of the carbonic actd accumulated by the repeated contractions of the muscles during the lesson. They may also with advantage be taken in the courke of physical training lessons or other. school work.

The following are the Exercises 50, 52, 53, 54 referred to above:

$$
\text { 50.-Arms Sideways Raising. }
$$

Arms Sideways-Raise (One).-Raise the arms sidewass in line with the shoulders, fingers extended, and palms downward.

Downward-Lower (Two).-Lower the arms to the sides.

(a) Heels Raising at One and Lowering at Two may be added later, the commands then being With Heels Raising, Arms Sideways-Raise; Dounward-Lower.

$$
52-A r m s \text { Forward and Upward Raising. }
$$

Arms Forward and Upward-Raise (One).- Raise the arms forward and continue the movement upward ill the arms are in the Upward Stretch position.

Forward and Downward-Lnwer (Two).-Lower the arms forward and downward to the sides, keeping the arms parallel and the palms inward.

Arms Sideways-Raise (One). $-\Delta \mathrm{s}$ in 50.

$$
\text { 53.-Arms Sideways and Upward Raising. }
$$

Upward-Raise (Two).-Keeping the arms strajgbt and well back, turn the palms smartly upward and immediately raise the arms until they are vertical above the shoulders.

Sideways-Lower (Three).-Lower the arms sideways to the level of the shoulders, keeping the palms upward and arms well drawn back.

Downward-Lower (Four). - Turn the palms smartly downward and lower the arms to the sideg.

After some practice the Sideways and Upward Raising should be done in one continuous movement on the command Arms Sideways and Upward-Raise (One) the palms being turned upward on passing the level of the shoulder. On the command sideways and Downward-Lower (Two) the arms should be brought to the position of Attention by reversing the movement.

(a) Heels Raising at One and Louering at Tuo may be added Jater, the commands then being With Heels Raising, Arms Sideways and UpwardRaise; Sideuays and Dounward-Louer.

54.-Arms Circling.

Arms Forward and Upward-Raise (One) - Raise the arms slowly forward and upward as in 52 .

Sideways and Downward-Lower (Two).-Keeping the arms well back, lower them sideways and downward as in 53 .

(a) Hetls Raising at One and Lowering at Two may be added Jater, the commands then being With Heels Raising, Arms Forvard and UpwardRaise; Sideways and Dounward-Lower.

\section{SYPHILIS AND INSANITY.}

\section{A Corkection.}

Is the article on the Prevalence and Prevention of Syphilia, published in the British MEdical Journal of January $14^{\mathrm{h} h}$, 1905, page 97, it was stated that Dr. Mott, when questioned ar to the relation of syphilis in ineanity, said that syphilis way the cause in between 25 and 45 per cent. of the men admitted. As this may give an erroneous impreseion of the view expressed by Wr. Mott, we quote the question and answer from the Minutes of Evidence :

ro, 479. You trace syphilis as one of the causes of most of the organic disesses of the nervous system?-I would not say most, but I flud in a great many of the cases of men between 25 and 45 coming into the hospitals, syphilis is the cause.

THE GRIFFITHS TESTIMONIAL FUND.

\begin{tabular}{|c|c|c|c|c|}
\hline ount previously ac & dged & ... & ... & 3018 \\
\hline L. H. Viellett ... & $\ldots$ & $\ldots$ & ... & 0 ro \\
\hline Dr. W. C. Humphreys & ... & $\cdots$ & .. & \\
\hline Hastings Torney... & $\ldots$ & .. & $\cdots$ & \\
\hline r. T. D. Griffths $\ldots$ & .. & .. & $\cdots$ & \\
\hline Dr. Evan Jones & $\cdots$ & $\cdots$ & $\cdots$ & \\
\hline Dr. J. D. M. & $\ddot{m}$ & 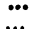 & $\ldots$ & \\
\hline
\end{tabular}

Dr. A. P. Fiddian (23, The Walk, Cardifi), Treasurer of this Fund, has received the following further subscriptions:

The object and particulars of the fund were stated in our columns of January 21st, 1905, p. 160. 